S. K. Guthrie $\cdot$ J.-K. Zubieta $\cdot$ L. Ohl $\cdot$ L. Ni

R. A. Koeppe $\cdot$ S. Minoshima $\cdot$ E. F. Domino

\title{
Arterial/venous plasma nicotine concentrations following nicotine nasal spray
}

Received: 15 February 1999 / Accepted in revised form: 17 August 1999

\begin{abstract}
Background and objectives: Arterial (A) and venous $(\mathrm{V})$ plasma nicotine and cotinine concentrations were measured after nasal nicotine spray in tobacco smokers of both genders. The hypothesis for this research was that a greater $\mathrm{A} / \mathrm{V}$ difference in plasma nicotine would be present in males than females because males have greater skeletal muscle mass to bind nicotine. Subjects and methods: Nine male and nine female healthy adult smokers were studied. They all abstained from use of tobacco overnight for $10 \mathrm{~h}$ or more prior to the study. Nicotine nasal spray was given in doses of $1-2.5 \mathrm{mg}$ total, with half in each nostril while the subject was supine. Both $\mathrm{A}$ and $\mathrm{V}$ blood samples were obtained prior to and $3,6,10,15,20$, and 30 min post-nasal nicotine spray.

Results and conclusions: Nasal nicotine administration produced greater $\mathrm{A}$ than $\mathrm{V}$ plasma levels. There were no gender differences in $\mathrm{A} / \mathrm{V}$ nicotine concentrations, disproving the above hypothesis, suggesting that other physiochemical factors besides skeletal muscle mass must be involved. Heart rate increases correlated well with arterial plasma nicotine levels $(r=0.77)$. Males had less variance than females in the expected increase in arterial plasma nicotine concentrations with increased number of
\end{abstract}

E.F. Domino $(\bowtie) \cdot$ L. Ni

Department of Pharmacology, The University of Michigan,

1150W. Medical Center Drive, Ann Arbor,

MI 48109-0632, USA

Tel.: +1-734-7649115; Fax: + 1-734-7634450

S.K. Guthrie · J.-K. Zubieta

Department of Psychiatry, The University of Michigan,

Ann Arbor, MI, USA

R.A. Koeppe $\cdot$ S. Minoshima

Department of Nuclear Medicine Section of Internal Medicine,

The University of Michigan, Ann Arbor, MI, USA

J.-K. Zubieta · L. Ohl

Mental Health Research Institute, The University of Michigan,

Ann Arbor, MI, USA

S.K. Guthrie

College of Pharmacy, The University of Michigan,

Ann Arbor, MI, USA nasal sprays. Although there was considerable overlap, mean A cotinine concentrations were consistently slightly larger than $\mathrm{V}$ concentrations.

Key words Nicotine $\cdot$ Cotinine $\cdot$ Nasal administration

\section{Introduction}

It is generally agreed that venous blood drug concentrations are a valid index of arterial concentrations but only when equilibrium throughout the organism is achieved. Arterial blood perfuses all body tissues before equilibrium and a significant portion of drug may be taken up by these tissues. Consequently, the concentration of drug in arterial blood is a better index of the amount delivered to the site of pharmacological action. During this period, arterial concentrations would be more likely to correlate with pharmacological responses. However, arterial access, even in a peripheral extremity, is a more invasive procedure than venous access. This practical consideration prompts most investigators to obtain only venous blood samples. As part of a quantitative study using nasal nicotine administration on regional cerebral blood flow, it was possible to obtain both arterial and venous blood samples for assay of nicotine and cotinine from the forearms of a group of adult male and female tobacco smokers who abstained from tobacco use overnight prior to the study.

When samples are obtained from vessels in the arm, the difference between arterial and venous concentrations prior to equilibrium reflects primarily the distribution of nicotine into tissues in the forearm. The change of venous nicotine concentration over time is affected by the arterial concentration, the tissue to blood partition ratio, the volume of tissue, and the rate of tissue perfusion. Several investigators have reported nicotine arterial/venous (A/V) concentrations following smoking, nasal and/or intravenous nicotine in adult male volunteers [1-4]. It is well known that, in general, adult males have a larger skeletal muscle mass than 
females [5]. Hence, the hypothesis of the present research was that males would have a greater nicotine $\mathrm{A} / \mathrm{V}$ difference than females due to greater distribution of nicotine in skeletal muscle. This manuscript describes data that do not support this superficially attractive hypothesis, indicating that many factors affect the final concentration of a drug leaving a tissue. In addition to the mass of tissue, this concentration is certainly affected by the partition of nicotine between blood and skeletal muscle. In the process of completing this study, several other interesting relationships were discovered.

\section{Subjects and methods}

This study was approved by the Investigational Review Board for Human Subject Research at The University of Michigan Medical Center. All candidates who agreed to participate provided informed consent. Subjects were recruited through advertisements in local newspapers and via community bulletin boards. Candidates who appeared to be eligible on the basis of a preliminary telephone screen were invited to a screening interview, at which time the study was explained. A physical examination was performed and laboratory tests were obtained, including a complete blood count, electrolytes, liver function tests, a urinalysis, and a urine toxicology screen for abused drugs. Additionally, all candidates underwent a psychiatric screening interview using the Diagnostic Interview Schedule. Women were given a pregnancy test prior to inclusion in the study. Subjects who met the above criteria completed a Fagerström test [6] to provide a preliminary assessment of degree of nicotine dependence.

\section{Inclusion and exclusion criteria}

Subjects were male or female tobacco smokers ( $>15-40$ cigarettes per day), between 18 years and 52 years of age, in good physical health, and not taking any medications (except oral contraceptives or replacement hormones). Individuals suffering from renal, hepatic, cardiovascular, hematological, neurological, psychiatric, or endocrinological disease were excluded. Fertile women who were not using an acceptable method of birth control (oral contraceptives, a barrier method, intrauterine device, or levonorgestrel implants) were excluded. Also, those who met criteria for psychoactive substance abuse disorder on the Diagnostic Interview Schedule were excluded, as were those who revealed evidence of recent use of an abused substance in the urine toxicological screen.

\section{Procedure}

Subjects included in the study were taught to use a Food and Drug Administration (FDA) approved nicotine nasal spray device prior to the study day. This study was conducted in conjunction with an evaluation of regional cerebral blood flow. Subjects reported to the PET suite of the Nuclear Medicine Division of University Hospital at 0800 hours on the day of the study, following overnight abstinence from tobacco and nicotine spray $(>10 \mathrm{~h})$. A sample of expired air was analyzed for carbon monoxide $(\mathrm{CO})$ in parts per million (ppm). Expired air CO levels higher than $10 \mathrm{ppm}$ in the subject required an extensive interview to ascertain possible noncompliance with the no-smoking directive within the past $10 \mathrm{~h}$. Also electrocardiogram (ECG) and blood pressure were monitored throughout the study (Marquette Electronics, Inc., Milwaukee, Wisc.; Series 7000 monitor).

Following an explanation of the imaging procedure, the subject lay supine on the positron emission tomography (PET) frame, and a series of six PET scans was conducted using $\mathrm{H}_{2}{ }^{15} \mathrm{O}$ to determine regional cerebral blood flow (rCBF). The methodology and results of the rCBF studies will be reported elsewhere [7]. Both venous and arterial access lines were placed in the forearms of the subjects prior to the rCBF sessions. Just before the fifth scan, nicotine spray $(0.5 \mathrm{mg} /$ spray $)$ was administered intranasally. Two to five sprays were given, depending on the volunteer's ability to tolerate the nicotine. Arterial and venous blood samples for nicotine and cotinine were withdrawn before and after the fifth and sixth scans. Samples were drawn prior to and at 3, 6, 10, 15, 20 and $30 \mathrm{~min}$ following the nicotine dose. Samples were collected in standard 5-ml vacutainer tubes containing ethylene diamine tetraacetic acid (EDTA) and stored immediately on crushed ice. Immediately following completion of the study, the samples were centrifuged and plasma aliquots were frozen at $-20{ }^{\circ} \mathrm{C}$ until analysis. Venous and arterial samples were analyzed using high-performance liquid chromatography (HPLC) techniques [8]. The interassay coefficients of variation for nicotine and cotinine were $10.8 \%$ and $5.5 \%$, respectively. The intraassay coefficients of variation were $9.0 \%$ and $5.8 \%$ for nicotine and cotinine, respectively. The sensitivity of the assay was $1 \mathrm{ng} / \mathrm{ml}$ for nicotine and $3 \mathrm{ng} / \mathrm{ml}$ for cotinine.

\section{Data analysis}

The maximum concentration $\left(\mathrm{C}_{\max }\right)$, the time of maximum concentration $\left(t_{\max }\right)$, and the area under the plasma concentration versus time curve (AUC) from 0 min to 30 min were determined for both arterial and venous nicotine concentrations directly from the observed data and by the linear trapezoidal rule. Analyses were run using raw data values as well as data adjusted for baseline nicotine concentration. The arterial and venous pharmacokinetic parameters were compared using paired $t$-tests. The pharmacokinetic values for males and females were compared using unpaired $t$-tests. Venous and arterial nicotine concentrations were compared using analysis of variance (ANOVA) for repeated measures. All statistical tests were conducted using SAS software [9] on a Macintosh power personal computer. Change in heart rate and arterial nicotine concentrations were fitted to the sigmoid $\mathrm{E}_{\max }$ model using PC NONLIN [10].

\section{Results}

Nineteen smokers were recruited (ten men, nine women). Data from one male subject were discarded, because the number of blood samples obtained was inadequate to determine pharmacokinetic parameters. Results are reported for 18 subjects (nine men and nine women). The mean age of the women was $33.7 \pm 8.38$ years (range 20-46 years) and the mean age of the men was $30.4 \pm$ 10.6 years (range 20-52 years). Outcomes of the analyses did not differ when adjusted for baseline plasma nicotine concentrations.

Overall, when arterial were compared with venous nicotine concentrations, ANOVA for repeated measures revealed both group $(P<0.01)$ and time $(P<0.01)$ effects, indicating that arterial concentrations were consistently and significantly higher than venous concentrations and that concentrations varied significantly over time (Fig. 1). The AUC and the $\mathrm{C}_{\max }$ values were also significantly larger when arterial were compared with venous concentrations $\left(P<0.001\right.$, for both). Also, $\mathrm{t}_{\max }$ occurred earlier in arterial than in venous samples $(5.06 \mathrm{~min}$ vs 16.66 min, respectively; Table 1). A comparison of the results by gender revealed no significant effects for $C_{\max }$, $\mathrm{AUC}, \mathrm{t}_{\max }$, or the ratio of arterial to venous $\mathrm{C}_{\max }$ or $\mathrm{AUC}$.

Mean arterial cotinine concentrations were consistently slightly greater than mean venous levels, especially 
Fig. 1 Mean arterial and venous plasma nicotine and cotinine concentrations following nasal nicotine administration. The mean \pm SEM of 18 tobacco smokers who were abstinent overnight is plotted before and after nasal nicotine spray to both nostrils

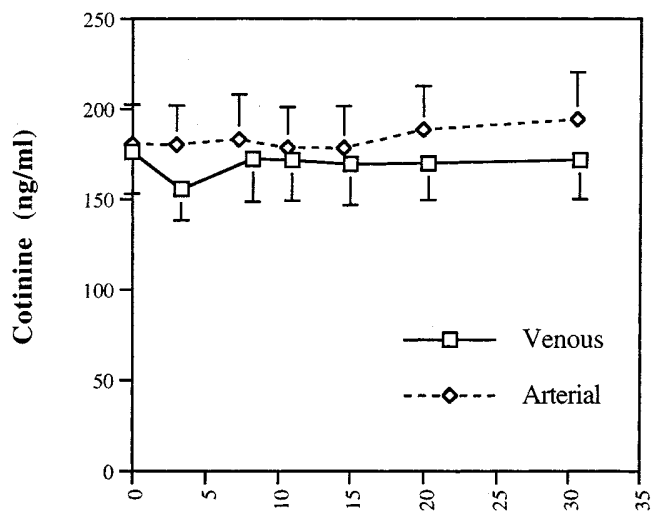

Time (min)

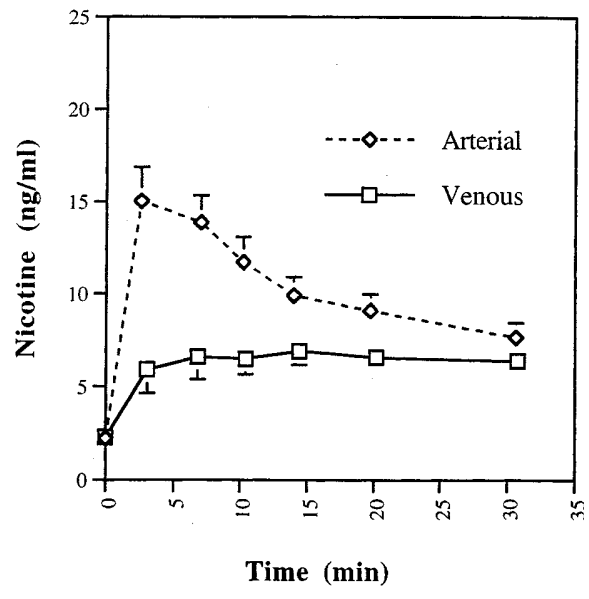

$20 \mathrm{~min}$ and $30 \mathrm{~min}$ post-nicotine nasal spray (Fig. 1). The standard errors overlapped considerably, but a trend analysis indicated that the mean differences were significant $(P<0.05)$. The arterial, but not the venous, $\mathrm{C}_{\max }$ was significantly correlated with the maximum change of heart rate $(P<0.001, r=0.77$; Fig. 2$)$. A more meaningful relationship between change in heart rate and arterial blood concentration might be obtained by fitting the data to a sigmoid $\mathrm{E}_{\max }$ model. Of the 18 subjects, an acceptable fit to the sigmoid $\mathrm{E}_{\max }$ model was achieved in 10 (Table 2). The mean maximum change in heart rate was $45.5 \mathrm{bpm}$ and the $\mathrm{EC}_{50}$ was $16.8 \mathrm{ng} / \mathrm{ml}$ (Fig. 3).

Two to five nasal sprays of nicotine were administered to each of the volunteers. The females showed much more variability in the boost in arterial nicotine than the males (Table 1). No significant linear relationship could be obtained between the number of nasal sprays and the increase in arterial nicotine levels when the female and male data were combined or for the females alone. The males had a correlation coefficient of $r=0.74(P<$ 0.05 ), indicating a linear increase in arterial nicotine as a function of number of nasal nicotine sprays.

\section{Discussion}

Possible gender-based differences in nicotine plasma concentrations following intranasal nicotine have not been explored previously. The concentration of nicotine in blood is affected by both the route of administration

Table 1 Gender, body weight, maximum concentration $\left(\mathrm{C}_{\max }\right)$, time to $\mathrm{C}_{\max }\left(\mathrm{t}_{\max }\right)$, and the area under the curve (AUC) for arterial and venous plasma nicotine concentrations

\begin{tabular}{|c|c|c|c|c|c|c|c|c|}
\hline \multirow[t]{2}{*}{ Subject no. } & \multirow{2}{*}{$\begin{array}{l}\text { Body } \\
\text { weight (kg) }\end{array}$} & \multirow{2}{*}{$\begin{array}{l}\text { No. of } \\
\text { nicotine } \\
\text { sprays }\end{array}$} & \multicolumn{3}{|l|}{ Arterial } & \multicolumn{3}{|l|}{ Venous } \\
\hline & & & $\mathrm{C}_{\max }(\mathrm{ng} / \mathrm{ml})$ & $t_{\max }(\min )$ & AUC & $\mathrm{C}_{\max }(\mathrm{ng} / \mathrm{ml})$ & $\mathrm{t}_{\max }(\min )$ & AUC \\
\hline 1 & 54.6 & 4 & 25.1 & 10 & 532.9 & 12.9 & 16 & 294.3 \\
\hline 4 & 61.8 & 2 & 8.1 & 6 & 164.4 & 4.5 & 19 & 99.9 \\
\hline 5 & 47.7 & 4 & 30.8 & 2 & 485.2 & 10.6 & 21 & 282.3 \\
\hline 6 & 59.1 & 3 & 16.3 & 3 & 270.2 & 8.9 & 60 & 222.6 \\
\hline 12 & 59.1 & 3 & 22.0 & 2 & 269.7 & 5.5 & 30 & 130.9 \\
\hline 16 & 68.2 & 4 & 15.4 & 7 & 244.5 & 3.8 & 20 & 115.5 \\
\hline 19 & 97.7 & 2 & 18.7 & 3 & 305.4 & 6.8 & 9 & 167.0 \\
\hline Mean \pm SD & $63.0 \pm 14.2$ & $3.3 \pm 0.9$ & $17.8 \pm 7.2$ & $4.7 \pm 2.9$ & $294.8 \pm 135.1$ & $7.2 \pm 2.9$ & $23.3 \pm 15.8$ & $170.0 \pm 79.0$ \\
\hline \multicolumn{9}{|l|}{ Male } \\
\hline 2 & 77.3 & 2 & 15.3 & 7 & 336.9 & 9.6 & 7 & 226.8 \\
\hline 14 & 72.7 & 2.5 & 13.5 & 3 & 250.1 & 11.7 & 4 & 193.9 \\
\hline 15 & 86.4 & 5 & 19.0 & 8 & 275.5 & 9.3 & 15 & 212.8 \\
\hline 17 & 75.0 & 4 & 13.2 & 6 & 244.5 & 3.8 & 20 & 95.6 \\
\hline 18 & 75.0 & 4 & 21.3 & 7 & 428.3 & 9.7 & 7 & 266.3 \\
\hline Mean \pm SD & $78.0 \pm 7.7$ & $3.4 \pm 1.1$ & $16.2 \pm 4.5$ & $5.4 \pm 2.2$ & $296.3 \pm 130.1$ & $9.1 \pm 4.8$ & $11.8 \pm 5.8$ & $203.5 \pm 108.2$ \\
\hline $\begin{array}{l}\text { Overall } \\
\quad \text { mean } \pm \mathrm{SD}\end{array}$ & $70.5 \pm 13.5$ & $3.3 \pm 1.0$ & $17.0 \pm 5.9$ & $5.1 \pm 2.5$ & $295.5 \pm 128.7$ & $8.2 \pm 4.0$ & $17.6 \pm 13.0$ & $186.8 \pm 93.5$ \\
\hline
\end{tabular}




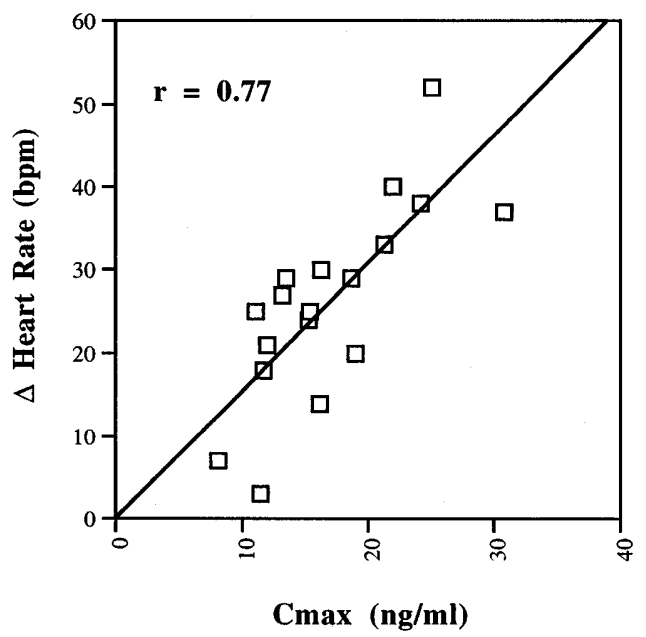

Fig. 2 Relationship between change of heart rate and the maximal arterial plasma nicotine concentration. The correlation between the arterial concentrations and heart rate per minute was $r=0.77$ in all 18 patients

and the site of blood sampling. When nicotine is administered intranasally, it is absorbed through the numerous small vessels surrounding the nasal sinuses. The veins of the nasal cavity form a cavernous plexus beneath the mucous membrane. In addition, arteriovenous communications are present [11]. These vessels ultimately drain into the superior vena cava. Venous nicotine is carried to the right side of the heart, followed by the lungs, where some nicotine is undoubtedly extracted by lung tissue. Following transport through the lungs, the oxygenated arterial blood is transported through the left side of the heart, carrying nicotine to all body organs and tissues.

Substances that are used primarily for their central nervous system effects, such as nicotine, are usually highly lipophilic and enter the brain shortly following ingestion. In the immediate period following a single dose of drug, the venous concentrations generally do not closely reflect body tissue concentrations in organs due to distributional lag time and distribution into or biotransformation of the drug by body tissues. It is known that there is a pronounced difference between the arterial and venous concentrations of nicotine following intravenous injection, smoking, or intranasal administration

Table 2 Best fit $\mathrm{E}_{\max }, \mathrm{ED}_{50}$, and gamma values for ten subjects $($ mean \pm SEM)

\begin{tabular}{llcc}
\hline Subject no. & $\mathrm{E}_{\max }$ & $\mathrm{EC}_{50}$ & Gamma \\
\hline 1 & $52.1 \pm 74.3$ & $15.7 \pm 45.5$ & $14.2 \pm 2334.9$ \\
3 & $71.2 \pm 1044.4$ & $31.4 \pm 272.1$ & $2.3 \pm 4.0$ \\
6 & $27.4 \pm 2.4$ & $6.9 \pm 0.25$ & $9.2 \pm 3.9$ \\
9 & $15.9 \pm 8.0$ & $4.1 \pm 3.0$ & $2.0 \pm 2.9$ \\
12 & $44.1 \pm 14.9$ & $6.4 \pm 1.9$ & $1.8 \pm 2.2$ \\
13 & $34.1 \pm 105.4$ & $33.0 \pm 111.4$ & $1.6 \pm 1.8$ \\
14 & $56.3 \pm 813.5$ & $21.8 \pm 518.9$ & $1.1 \pm 5.8$ \\
15 & $36.7 \pm 73.1$ & $10.1 \pm 13.8$ & $3.1 \pm 5.0$ \\
16 & $44.2 \pm 89.1$ & $13.3 \pm 32.8$ & $1.6 \pm 2.0$ \\
17 & $73.3 \pm 815.7$ & $25.4 \pm 369.3$ & $1.3 \pm 3.8$ \\
\hline
\end{tabular}

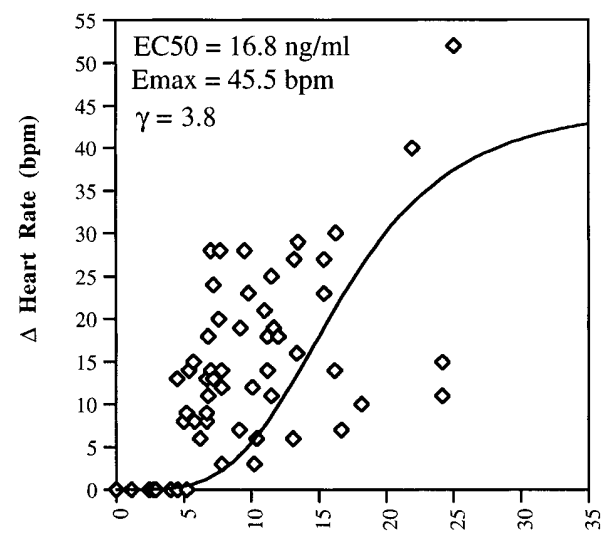

Arterial Nicotine Concentration (ng/ml)

Fig. 3 Relationship between change of heart rate and arterial plasma nicotine concentrations. Mean $\mathrm{E}_{\max }, \mathrm{EC}_{50}$, and gamma are depicted as the solid line. The arterial plasma concentrations and changes in heart rate from ten subjects are reported

of nicotine [1-4]. This differential between venous and arterial nicotine concentrations is due to the relationship between the site of administration of nicotine in relation to the site of measurement [12]. Because of nicotine distribution into and binding to various body tissues following intravenous or intrapulmonary administration, arterial concentrations are higher than venous concentrations in the short period following acute nicotine administration, until the drug has accumulated in the tissues and the net removal from arterial blood becomes zero [12, 13].

The hypothesis that men will exhibit a greater $\mathrm{A} / \mathrm{V}$ difference in nicotine concentrations due to greater skeletal muscle mass than women was not supported by the results of the present study. It is possible that, in the forearm, the larger skeletal muscle mass in men is offset by a higher proportion of subcutaneous fat in women. The blood perfusion rate is slightly higher in fat $(0.03 \mathrm{ml} / \mathrm{min} / \mathrm{ml}$ tissue $)$ than in inactive skeletal muscle (0.025 $\mathrm{ml} / \mathrm{min} / \mathrm{ml}$ tissue) [14]. In addition to perfusion rate and volume of tissue, the time to reach equilibrium depends on the tissue partition coefficient. Nicotine has a very high octanol-water coefficient (15:1 at $\mathrm{pH} 7$ ), which would contribute to rapid uptake in fatty tissues that is perfusion rate limited. For a tissue where there is no elimination, the mass/balance of a compound entering and leaving a tissue is given by:

$V \mathrm{~d} c / \mathrm{d} t=Q\left(C_{\text {in }}-C_{\text {in }} / K_{\mathrm{p}}\right)$

where $V$ is the physical volume of the tissue, $c$ is the drug concentration in the tissue, $t$ is the time, $Q$ is the blood flow to the tissue, $C_{\text {in }}$ is the drug concentration entering the tissue, and $K_{\mathrm{p}}$ is the partition of the drug between blood and the tissue. Thus, there are many factors that affect the final concentration of a drug leaving a tissue. In the case of nicotine, the dominant factor is probably partition and not the physical volume of skeletal muscle of men versus women. It is known that the 
pharmacokinetics of nicotine, when measured in venous blood, do not differ between men and women [15].

The trend for mean cotinine in arterial plasma to be greater than mean venous concentrations was unexpected. Various tissues, especially the liver and lung, biotransform nicotine to cotinine. Arterial blood going to and venous blood returning from the hand and forearm would not be expected to show any differences in concentration with a more water-soluble substance, such as cotinine, relative to nicotine. Apparently, the tissues in the forearm and hand retain a small amount of cotinine, especially $20 \mathrm{~min}$ and $30 \mathrm{~min}$ post nasal nicotine. After overnight nicotine deprivation of $10 \mathrm{~h}$ or more, the mean cotinine levels in both artery and vein were almost identical, indicating equilibration did occur and was almost complete.

Following nasal insufflation of nicotine, it has been estimated that approximately $20-30 \%$ of a nicotine dose is transported by the oral cavity and esophagus to the stomach. In the present study, the subjects were supine. It is quite likely that some intranasally administered nicotine also dripped into the pharynx where it was swallowed and ultimately absorbed, slowly, via the gastrointestinal tract. In addition, following nicotine nasal spray, the maximum arterial nicotine concentrations were higher, and occurred earlier, than the venous nicotine concentrations. Similar results have been reported previously [1]. The mean peak arterial concentration occurred after approximately $5 \mathrm{~min}$ in the present study. The actual value of the peak concentration differed from that found in the previous study of Gourlay and Benowitz [1], but this is not surprising because differing doses of nasal spray were delivered in our study.

In a study of smoking suppression following a 15$\mu \mathrm{g} / \mathrm{kg}$ and $30-\mu \mathrm{g} / \mathrm{kg}$ dose of nasal nicotine spray, subsequent cigarette smoking was suppressed to a greater extent in men than in women [16]. This is consistent with the present finding that women have greater variability in absorbing nasal nicotine than men. However, mean venous nicotine concentrations did not differ between men and women. Neither the pharmacokinetic parameters nor the relationship between change in heart rate and nicotine concentration showed any gender dependence. There was a statistically significant correlation between the change from baseline to maximum heart rate and maximum arterial nicotine concentration. Nevertheless, the correlation between these two measures was not affected by gender. In the present study, there was no gender difference in heart rate response. It is possible that heart rate response is not a good measure of central nicotine response and does not correlate well with other central nervous system responses to nicotine, such as suppression of craving or anxiety reduction. Unfortunately, at this time, there are no good objective measures that have been shown to unambiguously reflect central nervous system dynamic response to nicotine.

It is also possible that the small sample size may have caused a type-II error and obscured any gender-related differences that may, in fact, exist. This is unlikely because there was not even a trend indicating possible gender dependence of nicotine pharmacokinetics. The only gender difference noted in the present study was that the relationship between dose and arterial plasma concentration was more consistent in men than in women. A larger number of subjects is needed to show variation in arterial nicotine with the same number of nasal sprays in both genders.

Acknowledgments This research was supported by U.S. Public Health Service grant DA 10992 from the National Institute on Drug Abuse, National Institutes of Health. The authors would like to thank Dr. Cyrenius Jone and Mr. Peter Pathrose for conducting the nicotine and cotinine assays in this study.

\section{References}

1. Gourlay SG, Benowitz NL (1997) Arteriovenous differences in plasma concentration of nicotine and catecholamines and related cardiovascular effects after smoking, nicotine nasal spray, and intravenous nicotine. Clin Pharmacol Ther 62: 453-463

2. Henningfield JE, London ED, Benowitz NL (1990) Arterialvenous differences in plasma concentrations of nicotine after cigarette smoking. JAMA 253: 2050-2051

3. Henningfield JE, Stapleton JM, Benowitz NL, Grayson RF, London ED (1993) Higher levels of nicotine in arterial than in venous blood after cigarette smoking. Drug Alcohol Depend 33: $23-29$

4. Rose JE, Behm FM, Westman EC, Coleman RE (1999) Arterial nicotine kinetics during cigarette smoking and intravenous nicotine administration: implications for addiction. Drug Alcohol Depend (in press)

5. Snyder WS. Adopted by the International Commission on Radiological Protection (1992) Report of the Task Group on reference man. No. 23. Pergamon Press, New York, p 109

6. Fagerström KO, Heatherton TF, Kozlowski LT (1991) Nicotine addiction and its assessment. Ear Nose Throat J 69: 763-768

7. Domino EF, Zubieta J-K, Guthrie S, Ohl L, Ni L, Koeppe R, Cross D, Minoshima S (1999) Nicotine effects on regional cerebral blood flow in tobacco smokers (Abstr) Proceedings of Meeting of the Society for Neuroscience, Miami Beach, FL, October 23-28, Soc Neurosci [Abstr 25, Putl, p 285]

8. Hariharan M, VanNoord T, Greden JF (1988) A high-performance liquid-chromatographic method for routine simultaneous determination of nicotine and cotinine in plasma. Clin Chem 34: 724-7299

9. SAS (1996) Version 6.12. SAS Institute Inc, Cary, NC

10. SCI Software (1992) PC NONLIN Version 4.0, Lexington, KY

11. Warwick R, Williams PL (eds) (1973) Grays anatomy, 35th British edn. Saunders, Philadelphia, p 1177

12. Chiou WL (1989) The phenomenon and rationale of marked dependence of drug concentration on blood sampling site. Clin Pharmacokinet 17: 175-199

13. Gumbleton M, Øie S, Verotta D (1994) Pharmacokineticpharmacodynamic (PK-PD) modeling in non-steady-state studies and arterio-venous drug concentration differences. Br J Clin Pharmacol 38: 389-400

14. Rowland M, Tozer TN (eds) (1995) Clinical pharmacokinetics, concepts and applications, 3rd edn. Williams and Wilkins, Philadelphia, p 138

15. Benowitz NL, Jacob P (1994) Metabolism of nicotine to cotinine studied by a dual stable isotope method. Clin Pharmacol Ther 56: 483-493

16. Perkins KA, Grobe JE, Stiller RL, Fonte C, Goettler JE (1992) Nasal spray nicotine replacement suppresses cigarette smoking desire and behavior. Clin Pharmacol Ther 52: 627-634 